\title{
Adsorption kinetics and isotherms of arsenite and arsenate on hematite nanoparticles and aggregates
}

Dionne Dickson ${ }^{1}$, Guangliang Liu ${ }^{1}$ and Yong $\mathrm{Cai}^{1,2}$

${ }^{1}$ Department of Chemistry and Biochemistry and Southeast Environmental Research Center,

Florida International University, Miami, Florida, 33199, USA.

${ }^{2}$ Institute of Environment and Health, Jianghan University, Wuhan 430056, China

* Corresponding author. Tel.: 305-348-6210; Fax: 305-348-3772; Email address: cai@ fiu.edu 


\begin{abstract}
Iron (Fe) nanoparticles, e.g., zerovalent iron (ZVI) and iron oxide nanoparticles (IONP), have been used for remediation and environmental management of arsenic (As) contamination. These Fe nanoparticles, although originally nanosized, tend to form aggregates, in particular in the environment. The interactions of As with both nanoparticles and micron-sized aggregates should be considered when these Fe nanomaterials are used for mitigation of As issue. The objective of this study was to compare the adsorption kinetics and isotherm of arsenite (As(III)) and arsenate $(\mathrm{As}(\mathrm{V}))$ on bare hematite nanoparticles and aggregates and how this affects the fate of arsenic in the environment. The adsorption kinetic process was investigated with regards to the aggregation of the nanoparticles and the type of sorbed species. Kinetic data were best described by a pseudo second-order model. Both As species had similar rate constants, ranging from 3.82 to $6.45 \times 10^{-4} \mathrm{~g} /(\mu \mathrm{g} \cdot \mathrm{h})$, as rapid adsorption occurred within the first $8 \mathrm{~h}$ regardless of particle size. However, hematite nanoparticles and aggregates showed a higher affinity to adsorb larger amounts of $\mathrm{As}(\mathrm{V})(4122 \pm 62.79 \mu \mathrm{g} / \mathrm{g})$ than $\mathrm{As}(\mathrm{III})(2899 \pm 71.09 \mu \mathrm{g} / \mathrm{g})$ at equilibrium. We were able to show that aggregation and sedimentation of hematite nanoparticles occurs during the adsorption process and this might cause the immobilization and reduced bioavailability of arsenic. Isotherm studies were described by the Freundlich model and it confirmed that hematite nanoparticles have a significantly higher adsorption capacity for both $\mathrm{As}(\mathrm{V})$ and As(III) than hematite aggregates. This information is useful and can assist in predicting arsenic adsorption behavior and assessing the role of iron oxide nanoparticles in the biogeochemical cycling of arsenic.
\end{abstract}

Keywords: Arsenite; Arsenate; Iron oxide nanoparticles; Adsorption; Hematite aggregates 


\section{Introduction}

Contamination of surface and ground water by arsenic (As), a notoriously toxic element to humans and animals, has led to human population exposed to arsenic through drinking water or food, causing global health concerns (Carabante et al., 2009; Mandal and Suzuki, 2002; Zhang et al., 2002). Arsenic in the natural waters is predominantly in the inorganic forms: pentavalent arsenate (As(V)) or the trivalent arsenite (As(III)) (Ko et al., 2004; Zaspalis et al., 2007). The transport and transformation of arsenic in the environment include adsorption, ligand exchange, oxidation-reduction and precipitation (Banerjee et al., 2008). Adsorption to metal oxides particularly iron oxides to form inner-sphere complexes is one of the most significant factor controlling arsenic mobility in the environment (Al-Abed et al., 2006).

Studies have been conducted to investigate the adsorption of arsenic to bulk iron and iron oxides and their nanoparticles, and it was found that the process can be enhanced using zerovalent iron nanoparticles (NZVI) and iron oxide nanoparticles (IONPs) (Dixit and Hering, 2003). Iron oxides in general, whether in the bulk form or nanoparticulate form, have strong binding affinity for both arsenite and arsenate. The application of IONPs in contaminant remediation has enhanced the adsorption process due to the large surface area and its strong adsorption characteristics. These nanoparticles have increased adsorption capacity while maintaining many of the properties of bulk iron oxides. Numerous studies have investigated the adsorption behavior of arsenic with bulk iron oxides (Banerjee et al., 2008; Jain et al., 1999; Jeong et al., 2007; Zhang et al., 2004), as well as with bare/unmodified iron oxide nanoparticles (Auffan et al., 2008; Shipley et al., 2010; Turk et al., 2010; Tuutijarvi et al., 2009). Due to the strong binding affinity of iron oxides surface for arsenic and the development of nanotechnology as a potential remediation tool for arsenic contamination, it is of great interest that we evaluate 
the effects of IONPs on the fate and mobility of arsenate and arsenite in aqueous environment. The adsorption of arsenic and its retention on IONPs should be investigated while considering several factors such as the aggregation of the nanoparticles and the type of sorbed species.

Studies in the literature focusing on arsenic adsorption behavior with IONPs had failed to monitor IONPs particle size during adsorption. From our previous studies (Dickson et al., 2012) and other's (Zhang et al., 2008), IONPs tend to aggregate either at the initial stage of experiments and as time persist. These IONPS can grow to micron size particles during the adsorption process and will eventually sediment. This will influence the adsorptive properties of IONPs and its interaction with arsenic. Hence, previous studies on arsenic adsorption on IONPs in the literature, if not monitoring particle size and the aggregation occurred, might not be representative of the behavior of arsenic adsorption on nanoparticles. The potential aggregation of the nanoparticles can retard adsorption by reducing the surface area consequently decreasing IONPs reactivity and reducing the efficiency of arsenic adsorption (He et al., 2008). However, aggregation can be beneficial in the immobilization of arsenic by trapping the arsenic in the interior portions of the iron oxide aggregates thus reducing its bioavailability (Waychunas et al., 2005). Therefore, it is important to understand and demonstrate the difference of arsenic adsorption between nanoparticles and aggregates of iron oxides.

In this study, the adsorption/desorption process between nanoparticulate iron oxides and iron oxides aggregates was investigated with unmodified hematite $\left(\alpha-\mathrm{Fe}_{2} \mathrm{O}_{3}\right)$. Hematite is one of the most thermodynamically stable iron oxides and is usually the final stage of iron oxide phase transformations (Zaspalis et al., 2007). Phase transformation can be detrimental to adsorption since adsorbates can be desorbed and become bioavailable during the process. Therefore hematite has a greater potential for contaminant adsorption due to its stability. These hematite 
nanoparticles will have no surface modifications as modifiers could affect the sorption and desorption of contaminants on the nanoparticle surface, introduce additional mass transfer limitations of contaminants to active surface sites, and could decrease the reaction rate of the reactions that could be taking place at the surface (Phenrat et al., 2009). Therefore, we investigated and compared the adsorption process of As(V) and As(III) with hematite nanoparticles and larger aggregates. In this study, we utilized a probe ultrasonication dispersion method to produce IONPs from commercially bought nanoparticle powder and a conventional method to mimic IONPs that may be aggregated at the early stage of experiments. Our goal is to understand the kinetics and thermodynamics of arsenic-IONPs interactions, focusing on the size effect of nanoparticles on arsenic adsorption. In doing so, we will determine kinetic parameters, adsorption isotherms and adsorption capacities, thus evaluating the role of hematite nanoparticles and aggregates in the fate, mobility and bioavailability of arsenic in the environment.

\section{Procedures and Methods}

\subsection{Materials and Chemicals}

Commercial iron oxide nanoparticles $\left(\alpha-\mathrm{Fe}_{2} \mathrm{O}_{3}, 98 \%\right.$ purity and $50 \mathrm{~m}^{2} / \mathrm{g}$ specific surface area) were purchased from Nanostructured and Amorphous Materials (Houston, Texas). Stock solutions of $1000 \mathrm{mg} / \mathrm{L}$ and $10 \mathrm{mg} / \mathrm{L}$ As (III) and As (V) were prepared by dissolving sodium (meta)arsenite $\left(\mathrm{NaAsO}_{2}, 98 \%\right.$ purity) and sodium arsenate dibasic heptahydrate $\left(\mathrm{Na}_{2} \mathrm{HAsO}_{4} \cdot 7 \mathrm{H}_{2} \mathrm{O}, 99 \%\right.$ purity), respectively in $18.2 \mathrm{M} \Omega$ water produced from a Nanopure Diamond lab water system (Barnstead Thermolyne Corporation, Dubuque, IA). The arsenic standards were reagent grade and obtained from Aldrich Chemical Company (Milwaukee, WI.).

\subsection{Instrumentation}


Iron oxide nanoparticles were dispersed by probe ultrasonication using a Fisher Scientific sonic dismembrator model 100 (Pittsburg, PA) to prepare hematite nanoparticles . The IONPs were dispersed by vortex using a Fisher Scientific touch mixer model 232 (Pittsburgh, PA) to prepare micrometer size particles. Dynamic Light Scattering (DLS), a Malvern Zetasizer NanoZS (Westborough, MA.), was employed for particle size monitoring through measurement of hydrodynamic diameters of particles, representing the average particle diameter "z-average" intensity peak as a function of size. Total iron concentration was monitored using a graphite furnace atomic absorption spectrometer (GFAAS) (Perkin Elmer, model Aanalyst 600). The pH measurements were made using a Fisher Scientific Accumet Research AR $15 \mathrm{pH} / \mathrm{mV} /{ }^{\circ} \mathrm{C}$ Meter. Quantitative determination of arsenic concentration was conducted using Inductively Coupled Plasma-Mass Spectrometry (ICP-MS) (Perkin Elmer). Prior to arsenic analysis by ICP-MS, samples were centrifuged with a Fisher Marathon 21000R centrifuge (Needham Heights, MA).

\subsection{Experimental Procedures}

\subsubsection{Adsorption Kinetics Experiments.}

Adsorption studies were performed by mixing $10 \mathrm{mg} / \mathrm{L}$ hematite particles with $200 \mu \mathrm{g} / \mathrm{L}$ of $\mathrm{As}(\mathrm{V})$ or $\mathrm{As}(\mathrm{III})$ in $50 \mathrm{~mL}$ polypropylene centrifuge tubes. For nanoparticle experiments, IONPs were dispersed using probe ultrasonication for 20 minutes at power level 6 to generate hematite nanoparticles and the suspension was spiked with $200 \mu \mathrm{g} / \mathrm{L}$ of arsenic standard (10 $\mathrm{mg} / \mathrm{L}$ ). All samples were prepared in nanopure $18.2 \mathrm{M} \Omega$ water and the $\mathrm{pH}$ ranged from 6.8-8 as the suspensions were not buffered. Samples were agitated by pulsing with probe ultrasonicator regularly. Aliquots of samples $(2 \mathrm{~mL})$ were collected from 3 tubes for each sampling point at 
definite time intervals $\left(0-168 \mathrm{~h}, \mathrm{t}_{0 \mathrm{~h}}-\mathrm{t}_{168 \mathrm{~h}}\right)$ and the arsenic concentration in solution was monitored as a function of time.

The aliquots collected at the different time intervals $(0-168 \mathrm{~h})$ during the adsorption experiments were centrifuged for 60 minutes at $10000 \mathrm{rpm}$ for separation of particles from solution (See Supplementary Materials for selection of separation methods). The supernatant was analyzed for arsenic concentrations using ICP-MS. The amount of arsenic adsorbed was calculated from the difference between the initial and supernatant arsenic concentrations. The IONPs particle size was monitored during the adsorption experiment. IONPs concentration was also determined by measuring the total iron concentration in the suspensions using GFAAS in order to monitor the sedimentation of IONPs over time. Before iron analysis, IONPs suspension underwent acid digestion in 50\% nitric acid for 20 minutes at $95 \pm 5^{\circ} \mathrm{C}$.

For hematite aggregate experiments, adsorption was performed with similar procedures as described above except the aggregates were dispersed using vortex for 20 minutes at level 10 . This dispersion method generates particles in the micrometer size range (Dickson et al., 2012). The samples were agitated by shaking on an orbital shaker at $250 \mathrm{rpm}$ for the entire experimental time.

\subsubsection{Adsorption Isotherms.}

Hematite nanoparticles were dispersed similarly to procedures in the adsorption kinetics experiment. The hematite nanoparticles concentration was fixed at $10 \mathrm{mg} / \mathrm{L}$ and it was mixed with the appropriate amount of $10 \mathrm{mg} / \mathrm{L} \mathrm{As} \mathrm{(V)} \mathrm{or} \mathrm{As} \mathrm{(III)} \mathrm{stock} \mathrm{solutions} \mathrm{to} \mathrm{vary} \mathrm{the} \mathrm{arsenic}$ concentrations from 10-2000 $\mu \mathrm{g} / \mathrm{L}$. The As-IONPs dispersions were reacted to equilibrium (time 24h determined from kinetic experiment). The dispersions were agitated by pulsing with probe 
sonicator regularly. At equilibrium, $2 \mathrm{~mL}$ aliquots of samples were collected and the IONPs were separated from aqueous phase by centrifuging at $10000 \mathrm{rpm}$ for 60 minutes. Total arsenic concentrations in the supernatant were measured using ICP-MS. Additional $2 \mathrm{~mL}$ aliquots of samples were collected at equilibrium and the IONPs concentration was measured.

Isotherm experiments on hematite aggregates were performed with similar procedures as described above except the IONPs were dispersed using vortex. Samples were agitated by shaking on an orbital shaker at $250 \mathrm{rpm}$ for the entire experimental time.

\subsubsection{Quality Assurance of Sample Analysis.}

All kinetic and isotherm experiments were conducted in triplicate, and the average $( \pm$ standard deviation) was reported unless otherwise stated. For each batch of experiments, three procedure blanks without addition of As and three controls without addition of IONPs were included for monitoring of As contamination and loss (e.g., by adsorbed onto the container walls) during the course of experiments, respectively. It was found that As concentrations in all blanks were below method detection limit $(0.1 \mu \mathrm{g} / \mathrm{L})$ and loss of As through contacting with container walls was negligible.

\subsection{Data Processing}

For kinetic experiments, a kinetic fit of the data (the first $24 \mathrm{~h}$ ) was performed using a pseudo-second order kinetic model to determine initial rate constants and the amount of arsenic adsorbed at equilibrium (Azizian, 2004; Ho and McKay, 1999). This kinetic model (equation 1b) has been widely used to describe metal sorption onto different sorbents (Azizian, 2004; Ho and McKay, 1999). All data analysis and graphing were performed using the software OriginPro8. The pseudo second-order kinetic model for adsorption is expressed as: 
Non-Linear form:

$$
\frac{d q}{d t}=k_{2}\left(q_{e}-q_{t}\right)^{2}
$$

Linear form:

$$
\frac{t}{q_{t}}=\frac{1}{k_{2} q_{e}^{2}}+\frac{t}{q_{e}}
$$

$t$ is time (h)

$k_{2}$ is the rate constant of sorption $(\mathrm{g} /(\mu \mathrm{g} \cdot \mathrm{h}))$

$q_{e}$ is the equilibrium concentration of As adsorbed on particles $(\mu \mathrm{g} / \mathrm{g})$

$q_{t}$ is the As concentration adsorbed on particles at a certain time $(\mu \mathrm{g} / \mathrm{g})$

The plot of $t / q_{t}$ versus $t$ provides a straight line with slope of $1 / q_{e}$ and intercept of $1 / k_{2} q_{e}^{2}$. The values of $k_{2}$ and $q_{e}$ can be determined from the slope and intercept respectively.

To understand the adsorption equilibrium, the Freundlich isotherm was used to describe the adsorption equilibrium data for the adsorption of As(V) and As(III) with hematite nanoparticles and aggregates. This model best describes adsorption equilibrium on heterogeneous materials and assumes that there is an infinite supply of adsorbent sites. The Freundlich isotherm is expressed as (Banerjee et al., 2008; Duran et al., 2011; Skopp, 2009):

$$
q_{e}=K_{f} C_{e}^{1 / n}
$$

$q_{e}$ is the concentration of As adsorbed on particles at equilibrium $(\mu \mathrm{g} / \mathrm{g})$

$C_{e}$ is the equilibrium As concentration in solution $(\mu \mathrm{g} / \mathrm{L})$

$K_{f}$ is the Freundlich constant $\left(\mathrm{L}^{1 / \mathrm{n}} \cdot \mu \mathrm{g}^{1-1 / \mathrm{n}} / \mathrm{g}\right)$ 
$n$ is the dimensionless Freundlich adsorption intensity constant

\section{Results and Discussion}

\subsection{Adsorption Kinetics}

The adsorption of As(III) and As(V) to hematite nanoparticles was investigated at $\mathrm{pH} 7$ 8.0 which is the characteristic $\mathrm{pH}$ of many potable waters. The slight shift in $\mathrm{pH}$ was attributed to the samples being not buffered. There was no particular trend in $\mathrm{pH}$ variation as the $\mathrm{pH}$ increases and decreases randomly while remaining in the $\mathrm{pH} 7-8.0$ range throughout the experiment. These $\mathrm{pH}$ changes were not expected to affect the adsorption studies, as indicated by previous arsenic adsorption envelope studies (Raven et al., 1998). Figure 1a and Figure 2a show the adsorption curve of $\mathrm{As}(\mathrm{III})$ and $\mathrm{As}(\mathrm{V})$ with hematite nanoparticles respectively. Rapid adsorption was observed for As(III) and As(V) to hematite nanoparticles within the first $8 \mathrm{~h}$ after which the adsorption rate slowed and equilibrium was attained at $\sim 24 \mathrm{~h}$. There is a good fit for the secondorder kinetic model for adsorption as $\mathrm{R}^{2}>0.99$ (Figures $1 \mathrm{~b}$ and $2 \mathrm{~b}$ ). The initial rate constant $\left(k_{2}\right)$ for As(V) adsorption is $5.10 \times 10^{-4} \pm 1.40 \times 10^{-4} \mathrm{~g} /(\mu \mathrm{g} \cdot \mathrm{h})$ and $6.45 \times 10^{-4} \pm 3.11 \times 10^{-4} \mathrm{~g} /(\mu \mathrm{g} \cdot \mathrm{h})$ for As(III) adsorption (Table 1). There was no significant difference between the adsorption rate for As(III) and As(V) onto hematite nanoparticles. However, As(V) had a larger amount of adsorbate at equilibrium $\left(\mathrm{q}_{\mathrm{e}}=4122 \pm 62.79 \mu \mathrm{g} / \mathrm{g}\right)$ compared to $\mathrm{As}(\mathrm{III})\left(\mathrm{q}_{\mathrm{e}}=2899 \pm 71.09 \mu \mathrm{g} / \mathrm{g}\right)$ (Table 1).

The reactivity and the adsorption capabilities of hematite nanoparticles can be affected by the aggregation/growth of the particle from nanoparticulate sizes to micrometer size particles. Therefore, to determine if aggregation of the nanoparticles affects adsorption, the hydrodynamic diameter of the particles was monitored during the adsorption experiments. The hydrodynamic 
sizes at the beginning of experiment $\left(0 \mathrm{~h}, \mathrm{t}_{0 \mathrm{~h}}\right)$, although slightly outside the range of what is considered nanoparticles $(<100 \mathrm{~nm})$, are the minimum sizes that can be achieved using the probe ultrasonication dispersion method. From our previous work (Dickson et al., 2012) and others (Zhang et al., 2008), the dispersion of commercial nanoparticles to the originally acclaimed size by the manufacturer $(20-50 \mathrm{~nm})$ is difficult. The probe ultrasonicator cannot break down IONPs to its primary particle diameter due to possible aggregation of the particles during synthesis or long periods of storage. Figures $3 \mathrm{a}$ and $3 \mathrm{~b}$ show the particle size distribution during the adsorption experiments. During the period of rapid adsorption $(0-8 \mathrm{~h})$, hematite nanoparticles hydrodynamic diameter increased during As(V) and As(III) adsorption experiments. In the presence of $\mathrm{As}(\mathrm{V})$, the particle size drastically increased from $137 \mathrm{~nm}$ at $\mathrm{t}_{0 \mathrm{~h}}$ to $345 \mathrm{~nm}$ at $2 \mathrm{~h}\left(\mathrm{t}_{2 \mathrm{~h}}\right)$ but reduced to sizes similar to the control $(120-160 \mathrm{~nm})$ from $\mathrm{t}_{24-168 \mathrm{~h}}$. In the presence of As(III), the hematite nanoparticle size increased from $122 \mathrm{~nm}$ at $\mathrm{t}_{0 \mathrm{~h}}$ to $213 \mathrm{~nm}$ at $\mathrm{t}_{8 \mathrm{~h}}$ but reduced to sizes

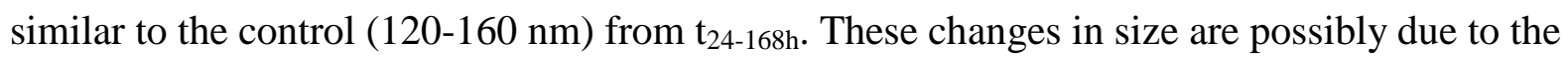
adsorption of arsenic to the hematite nanoparticle surface causing a change in the surface charge and increasing particle growth. Researchers studying the adsorption of arsenic to bulk ferrihydrite $(\mathrm{FeOOH})$ had found that there is a reduction in the surface charge of ferrihydrite when both arsenite and arsenate adsorb (Jain et al., 1999). Therefore, the surface charge properties of hematite nanoparticles can explain its aggregation when arsenic is adsorbed. At this $\mathrm{pH}\left(\mathrm{pH}\right.$ 6-8), $\mathrm{As}(\mathrm{III})$ is neutral $\left(\mathrm{H}_{3} \mathrm{AsO}_{3}{ }^{0}\right)$ and hematite nanoparticle is slightly positively charged (zeta potential $+29.8 \pm 0.917 \mathrm{mV}$ ). There is a possibility that the surface charge of hematite nanoparticle becomes suppressed when arsenite adsorbs. This caused the aggregation and sedimentation of the particles as evidenced by a reduction in the amount of IONPs in the dispersion from $\mathrm{t}_{0 \mathrm{~h}}$ to $\mathrm{t}_{8 \mathrm{~h}}$ (Figure $3 \mathrm{a}$ squares). On the other hand, $\mathrm{As}(\mathrm{V})$ is negatively charged 
$\left(\mathrm{H}_{2} \mathrm{AsO}_{4}{ }^{-}\right.$and $\left.\mathrm{HAsO}_{4}{ }^{2-}\right)$ at $\mathrm{pH}$ 6-8 and there is a strong electrostatic attraction between $\mathrm{As}(\mathrm{V})$ and the slightly positively charge nanoparticle. Therefore, the charge becomes neutralized during adsorption and this caused the particles to aggregate and sediment as evidenced by a reduction in the amount of hematite nanoparticles in the dispersion from $t_{0 h}$ to $t_{8 h}$ (Figure $3 b$ squares). After 8 $\mathrm{h}$, adsorption of arsenate and arsenite is minimal and the IONPs particle sizes are similar to those of the control (120-160 nm) with minimal sedimentation suggesting that the IONPs that remained in suspension is not bound by arsenic. These results are important as it can explain one mechanism in which arsenic might be immobilized causing a reduction in its bioavailability and mobility in the environment. The suppression or neutralization of the charge once arsenic adsorbs to hematite nanoparticles reduces any electrostatic repulsion between the nanoparticles causing them to come together and aggregate. Arsenic might be trapped in the interior portions of these aggregates and are removed from solution becoming immobile and unavailable for any biogeochemical processes.

These adsorption experiments also suggested that hematite nanoparticles have higher adsorption capacity for As(V) than for As(III). The surface charge properties is also a good explanation as to why higher amounts of $\mathrm{As}(\mathrm{V})$ than $\mathrm{As}(\mathrm{III})$ were adsorbed at equilibrium. The negatively charged As(V) has a stronger electrostatic attraction to the positively charged hematite particles than the electrically neutral As(III). Therefore, more As(V) was retained on hematite particles than As(III).

The adsorption of arsenic to hematite aggregates was investigated to determine the extent at which the reduction in surface area affects hematite reactivity and the efficiency of arsenic adsorption. Figures S2a and S3a shows the adsorption curve of As(III) and As(V) with hematite aggregates. There was rapid adsorption of $\mathrm{As}(\mathrm{III})$ and $\mathrm{As}(\mathrm{V})$ to hematite aggregates within the 
first $24 \mathrm{~h}$ after which there was desorption of arsenic between $24-72 \mathrm{~h}$, followed by slow adsorption. The causes of desorption is uncertain at this point, although arsenic species transformation might be possible causes of arsenic release from the particle surface (Islam et al., 2004; Pedersen et al., 2006; Tufano and Fendorf, 2008). Preliminary speciation experiments have shown that there is no arsenic species conversion within the first $24 \mathrm{~h}$ but conversion (from initially added As(III) to As(V), or vice verse) is observed at or after $48 \mathrm{~h}$. Future work involving speciation analysis of arsenic in the solution and on the particles could be helpful in determining whether speciation conversion can cause desorption of arsenic from the nanoparticle surface.

In order to compare the rate of adsorption between nanoparticles and large aggregates, a pseudo second order kinetic fit was also carried out for the first $24 \mathrm{~h}$ of adsorption for hematite aggregates (Figures $\mathrm{S} 2 \mathrm{~b}$ and $\mathrm{S} 3 \mathrm{~b})$. As $(\mathrm{V})$ had a larger amount of adsorbate at equilibrium $\left(\mathrm{q}_{\mathrm{e}}=\right.$ $2614 \pm 72.69 \mu \mathrm{g} / \mathrm{g})$ compared to As(III) $\left(\mathrm{q}_{\mathrm{e}}=1689 \pm 90.20 \mu \mathrm{g} / \mathrm{g}\right)($ Table 1$)$. The initial rate constant for As(V) adsorption is $4.60 \times 10^{-4} \pm 2.73 \times 10^{-4} \mathrm{~g} /(\mu \mathrm{g} \cdot \mathrm{h})$ and $3.82 \times 10^{-4} \pm 1.40 \times 10^{-4}$ $(\mathrm{g} / \mu \mathrm{g} \cdot \mathrm{h})$ for $\mathrm{As}(\mathrm{III})$ adsorption. There was no significant difference between the adsorption rate for $\mathrm{As}(\mathrm{III})$ and $\mathrm{As}(\mathrm{V})$ to hematite aggregates.

Overall there was no significant difference between the initial rate of adsorption of As(III) and $\mathrm{As}(\mathrm{V})$ to hematite nanoparticles and hematite aggregates since the fastest rate of adsorption occurred in the first $24 \mathrm{~h}$ regardless of the particle size. However, the amount of arsenic adsorbed at equilibrium was different depending on the size of the particle. Hematite nanoparticles adsorbed significantly more $\mathrm{As}(\mathrm{III})$ and $\mathrm{As}(\mathrm{V})$ at equilibrium compared to hematite aggregates. The large aggregates had smaller surface area resulting in a reduction in the adsorption efficiency.

\subsection{Adsorption Isotherm}


Figure 4 describes the Freundlich isotherm for the adsorption of $\mathrm{As}(\mathrm{V})$ and $\mathrm{As}(\mathrm{III})$ to hematite nanoparticles. The data had a good fit to the Freundlich model $\left(\mathrm{R}^{2}>0.9\right)$. The parameters from the Freundlich isotherm are summarized in Table 1. The Freundlich isotherm was also used to describe the adsorption equilibrium data for larger aggregates (Figure 5) and the data also had a good fit to this model $\left(\mathrm{R}^{2}>0.9\right)$. The $n$ value is the Freundlich constant for adsorption intensity, describing the degree of favorability of adsorption of one adsorbate to another (Duran et al., 2011). The ideal value of $\mathrm{n}$ should be between 1 and 10 for favorable adsorption according to McKay et al. who used a four-level system (unfavorable, linear, favorable, and irreversible) to evaluate the shapes of adsorption isotherms (McKay et al., 1982). For hematite nanoparticles $n$ is $1.66 \pm 0.18$ for $\mathrm{As}(\mathrm{V})$ and $1.50 \pm 0.13 \mathrm{As}(\mathrm{III})$. For hematite aggregates the $n$ values for $\mathrm{As}(\mathrm{V})$ and $\mathrm{As}(\mathrm{III})$ are $1.25 \pm 0.14$ and $1.40 \pm 0.086$, respectively. Based on these results, there were no significant difference between the favorability of adsorption of $\mathrm{As}(\mathrm{III})$ and $\mathrm{As}(\mathrm{V})$ to hematite nanoparticles or aggregates. Therefore hematite has a favorable adsorption for both $\mathrm{As}(\mathrm{V})$ and $\mathrm{As}(\mathrm{III})$ regardless of the particle size.

For hematite nanoparticles, the values of $K_{f}$ for $\mathrm{As}(\mathrm{V})$ and $\mathrm{As}(\mathrm{III})$ are $200 \pm 92.2$ and 101 \pm 44.0 , respectively. For the aggregates, the $K_{f}$ for $\mathrm{As}(\mathrm{V})$ and $\mathrm{As}(\mathrm{III})$ are $21.5 \pm 14.4$ and $26.8 \pm$ 8.74, respectively (Table 1). It is difficult to directly compare $K_{f}$ values in Freundlich isotherms, as the units of $K_{f}$ depend on the value of $1 / n$. The The values of $K_{f}$ parameter may have practical application for comparison when a certain solution concentration is given and the $1 / n$ parameters are the same (Coles and Yong, 2006; McKay et al., 1982). In this study, the $1 / n$ values were similar for $\mathrm{As}(\mathrm{III})$ and $\mathrm{As}(\mathrm{V})$ adsorption on both hematite nanoparticles and aggregates. The $K_{f}$ values for hematite nanoparticles were drastically different than for the aggregates, which might be indicative that nanoparticles may be able to adsorb more arsenic. 
The results of adsorption kinetics and isotherms suggest that the processes involved in arsenic adsorption on either hematite nanoparticles or aggregates could be similar, at least in part through electrostatic interactions between the surface charges of particles and the electric charges of arsenic species. Support for this notion came from the observations that pseudo second order kinetic model could apply to both nanoparticles and aggregates, and there were no significant differences in the initial adsorption rate constants. Moreover, in adsorption isotherm experiments, Freundlich model could describe well the data of nanoparticles and aggregates, and the $n$ values (adsorption intensity constant) were similar, indicative of similar types of interactions of arsenic with nanoparticle and with aggregates. The nanoparticles generated through probe ultrasonication had hydrodynamic diameters of $120-160 \mathrm{~nm}$, whereas the aggregates produced through conventional vortex method were mainly at the scale of microns ranging from 700 to $2400 \mathrm{~nm}$. The remarkably smaller sizes of nanoparticles would have much large specific surface area, in comparison to the larger size aggregates. As a result, hematite nanoparticles would be able to adsorb more $\mathrm{As}(\mathrm{III})$ and $\mathrm{As}(\mathrm{V})$ at equilibrium $\left(\mathrm{q}_{\mathrm{e}}=4122 \pm 62.79\right.$ and $2899 \pm 71.09 \mu \mathrm{g} / \mathrm{g}$, respectively) than hematite aggregates $\left(\mathrm{q}_{\mathrm{e}}=2614 \pm 72.69\right.$ and $1689 \pm 90.20 \mu \mathrm{g} / \mathrm{g}$, respectively). The differences in surface area between nanoparticles and aggregates were the major cause for the observed differences in the amounts of arsenic adsorbed on nanoparticles and aggregates. It should be noted that redox conditions could also play a role in arsenic adsorption on nanoparticles, as our preliminary experiments did show the interconversion between As(III) and $\mathrm{As}(\mathrm{V})$, but further studies are needed to explore the role of redox conditions in this process.

A comparison of the results from the isotherm studies confirmed that hematite nanoparticles have significantly higher adsorption capacity for both $\mathrm{As}(\mathrm{III})$ and $\mathrm{As}(\mathrm{V})$ compared to hematite aggregates. These nanoparticles are more reactive due to the higher amounts of 
adsorption sites compared to those of hematite aggregates. The high adsorption capacity and favorability for arsenic adsorption are key factors that will determine the extent at which hematite nanoparticles will affect the fate of arsenic in the environment. The results from the kinetic and isotherm studies indicate that nanoparticles will play a key role in the adsorption of arsenic in the environment subsequently affecting arsenic mobility and bioavailability. The interaction between the nanoparticle surface and arsenic can change the surface properties (such as surface charge) of the nanoparticles causing aggregation of the nanoparticles thereby influencing the fate of arsenic in the environment.

\section{Conclusions}

Kinetic and isotherm studies were performed to describe the adsorption process. Kinetic studies revealed that the pseudo-second order equation suitably described the adsorption kinetics of $\mathrm{As}(\mathrm{V})$ and $\mathrm{As}(\mathrm{III})$ to hematite nanoparticles and aggregates. The initial rate of adsorption of $\mathrm{As}(\mathrm{V})$ and $\mathrm{As}(\mathrm{III})$ onto hematite nanoparticle and aggregates was fastest within the first $8 \mathrm{~h}$. During this time, the hematite nanoparticles showed an increase in hydrodynamic diameter during the period of rapid adsorption. Hematite, whether in the nanoparticulate or aggregate form, showed a higher affinity to adsorb larger amounts of As(V) than As(III) at equilibrium. This difference is due to the surface charge, as $\mathrm{As}(\mathrm{V})$ is negatively charged at $\mathrm{pH}$ 6-8 and has a stronger electrostatic attraction to the positively charged hematite particles than the electrically neutral As(III). Therefore, more As(V) will be retained than As(III). The size of the particle also greatly influence the amount of arsenic adsorbed. Hematite nanoparticles significantly adsorb more $\mathrm{As}(\mathrm{V})$ and $\mathrm{As}(\mathrm{III})$ at equilibrium in comparison to hematite aggregates. Freundlich isotherm studies also showed that hematite nanoparticles has a significantly higher adsorption capacity for both As(V) and As(III) than hematite aggregates. 
Most importantly, we were able to show that aggregation and sedimentation of hematite nanoparticles did occur during the adsorption process especially in the period of rapid arsenic adsorption. This might assist in the immobilization and reduced bioavailability of arsenic because arsenic can be trapped during particle aggregation and be removed from solution during sedimentation. From the perspective of environmental remediation, this study implies that maintaining IONPs at nanometer scale for a period (e.g., at least $>8 \mathrm{~h}$ ) by using appropriate dispersion techniques is important for arsenic removal when IONPs are initially applied to the environment. Due to the interactions between arsenic and IONPs surface (e.g., charge suppression or neutralization) with the progression of arsenic adsorption, the IONPs would undergo aggregation and sedimentation, trapping and immobilizing arsenic within the aggregates. Further studies on continuous removal of the aggregates and applications of newly dispersed Fe oxide nanoparticles could be beneficial for more efficient removal of arsenic from the solution. This is important because arsenic become less mobile and less bioavailable. Therefore, hematite nanoparticles and its interactions with arsenic are important as these interactions play a role in the biogeochemical cycling of arsenic.

\section{Acknowledgements}

This research was sponsored by National Natural Science Foundation of China (No. 91543103) and the U.S. Department of Energy. Dionne Dickson acknowledges the financial support from the Dissertation Year Fellowship from Florida International University (FIU). This is contribution \# of the Southeast Environmental Research Center at FIU.

\section{References}


Al-Abed, S.R., Jegadeesan, G., Purandare, J., Allen, D., 2006. Arsenic release from iron rich mineral processing waste: influence of $\mathrm{pH}$ and redox potential. Chemosphere 66, 775-782.

Auffan, M., Rose, J., Proux, O., Borschneck, D., Masion, A., Chaurand, P., Hazemann, J.L., Chaneac, C., Jolivet, J.P., Wiesner, M.R., Van Geen, A., Bottero, J.Y., 2008. Enhanced adsorption of arsenic onto maghemites nanoparticles: $\mathrm{As}(\mathrm{III})$ as a probe of the surface structure and heterogeneity. Langmuir 24, 3215-3222.

Azizian, S., 2004. Kinetic models of sorption: A theoretical analysis. J. Colloid Interface Sci. 276, 47-52.

Banerjee, K., Amy, G.L., Prevost, M., Nour, S., Jekel, M., Gallagher, P.M., Blumenschein, C.D., 2008. Kinetic and thermodynamic aspects of adsorption of arsenic onto granular ferric hydroxide (GFH). Water Res. 42, 3371-3378.

Carabante, I., Grahn, M., Holmgren, A., Kumpiene, J., Hedlund, J., 2009. Adsorption of As(V) on iron oxide nanoparticle films studied by in situ ATR-FTIR spectroscopy. Colloids Surf., A 346, 106-113.

Coles, C.A., Yong, R.N., 2006. Use of equilibrium and initial metal concentrations in determining Freundlich isotherms for soils and sediments. Eng. Geol. 85, 19-25.

Dickson, D., Liu, G., Li, C., Tachiev, G., Cai, Y., 2012. Dispersion and stability of bare hematite nanoparticles: Effect of dispersion tools, nanoparticle concentration, humic acid and ionic strength. Sci. Total Environ. 419, 170-177.

Dixit, S., Hering, J.G., 2003. Comparison of arsenic(V) and arsenic(III) sorption onto iron oxide minerals: Implications for arsenic mobility. Environ. Sci. Technol. 37, 4182-4189.

Duran, C., Ozdes, D., Gundogdu, A., Senturk, H.B., 2011. Kinetics and isotherm analysis of basic dyes adsorption onto almond shell (prunus dulcis) as a low cost adsorbent. J. Chem. Eng. Data 56, 2136-2147.

He, Y.T., Wan, J., Tokunaga, T., 2008. Kinetic stability of hematite nanoparticles: The effect of particle sizes. J. Nanopart. Res. 10, 321-332. 
Ho, Y.S., McKay, G., 1999. Pseudo-second order model for sorption processes. Process Biochem. 34, 451465.

Islam, F.S., Gault, A.G., Boothman, C., Polya, D.A., Charnock, J.M., Chatterjee, D., Lloyd, J.R., 2004. Role of metal-reducing bacteria in arsenic release from Bengal delta sediments. Nature 430, 68-71.

Jain, A., Raven, K.P., Loeppert, R.H., 1999. Arsenite and arsenate adsorption on ferrihydrite: Surface charge reduction and net $\mathrm{OH}-$ release stoichiometry. Environ. Sci. Technol. 33, 1179-1184.

Jeong, Y., Fan, M., Singh, S., Chuang, C.-L., Saha, B., van Leeuwen, J.H., 2007. Evaluation of iron oxide and aluminum oxide as potential arsenic(V) adsorbents. Chem. Eng. Process. 46, 1030-1039.

Ko, I., Kim, J.-Y., Kim, K.-W., 2004. Arsenic speciation and sorption kinetics in the As-hematite-humic acid system. Colloids Surf. 234, 43-50.

Mandal, B.K., Suzuki, K.T., 2002. Arsenic round the world: A review. Talanta 58, 201-235.

McKay, G., Blair, H.S., Gardner, J.R., 1982. Adsorption of dyes on chitin. I. Equilibrium studies. J. Appl. Polym. Sci. 27, 3043-3057.

Pedersen, H.D., Postma, D., Jakobsen, R., 2006. Release of arsenic associated with the reduction and transformation of iron oxides. Geochim. Cosmochim. Acta 70, 4116-4129.

Phenrat, T., Liu, Y., Tilton, R.D., Lowry, G.V., 2009. Adsorbed polyelectrolyte coatings decrease Fe nanoparticle reactivity with TCE in water: Conceptual model and mechanisms. Environ. Sci. Technol. 43, 1507-1514.

Raven, K.P., Jain, A., Loeppert, R.H., 1998. Arsenite and arsenate adsorption on ferrihydrite: Kinetics, equilibrium, and adsorption envelopes. Environ. Sci. Technol. 32, 344-349.

Shipley, H.J., Yean, S., Kan, A.T., Tomson, M.B., 2010. A sorption kinetics model for arsenic adsorption to magnetite nanoparticles. Environ. Sci. Pollut. Res. 17, 1053-1062.

Skopp, J., 2009. Derivation of the Freundlich adsorption isotherm from kinetics. J. Chem. Educ. 86, 13411343. 
Tufano, K.J., Fendorf, S., 2008. Confounding impacts of iron reduction on arsenic retention. Environ. Sci. Technol. 42, 4777-4783.

Turk, T., Alp, I., Deveci, H., 2010. Adsorption of As(V) from water using nanomagnetite. J. Environ. Eng. 136, 399-404.

Tuutijarvi, T., Lu, J., Sillanpaa, M., Chen, G., 2009. As(V) adsorption on maghemite nanoparticles. Journal of Hazardous Materials 166, 1415-1420.

Waychunas, G.A., Kim, C.S., Banfield, J.F., 2005. Nanoparticulate iron oxide minerals in soils and sediments: unique properties and contaminant scavenging mechanisms. J. Nanopart. Res. 7, 409-433.

Zaspalis, V., Pagana, A., Sklari, S., 2007. Arsenic removal from contaminated water by iron oxide sorbents and porous ceramic membranes. Desalination 217, 167-180.

Zhang, W., Cai, Y., Tu, C., Ma, L.Q., 2002. Arsenic speciation and distribution in an arsenic hyperaccumulating plant. Sci. Total Environ. 300, 167-177.

Zhang, W., Singh, P., Paling, E., Delides, S., 2004. Arsenic removal from contaminated water by natural iron ores. Miner. Eng. 17, 517-524.

Zhang, Y., Chen, Y., Westerhoff, P., Hristovski, K., Crittenden, J.C., 2008. Stability of commercial metal oxide nanoparticles in water. Water Res. 42, 2204-2212. 


\section{Figures Legends}

Figure 1 (a) Plot of arsenite adsorbed ( $\mu \mathrm{g}$ As(III)/g IONPs) versus time (h). (b) Linear PseudoSecond Order Kinetic Fit for the adsorption of As(III) to hematite nanoparticles.

Figure 2 (a) Plot of arsenate adsorbed ( $\mu$ g As(V)/g IONPs) versus time (h). (b) Linear PseudoSecond Order Kinetic Fit for the adsorption of As(V) to hematite nanoparticles

Figure 3 Particle size distribution and IONPs concentration monitored during adsorption experiment (a) As(III) and (b) As(V)

Figure 4 Freundlich Isotherm of (a) As(III) and (b) As(V) with hematite nanoparticles

Figure 5 Freundlich Isotherm of (a) As(III) and (b) As(V) with hematite aggregate 
Figure 1
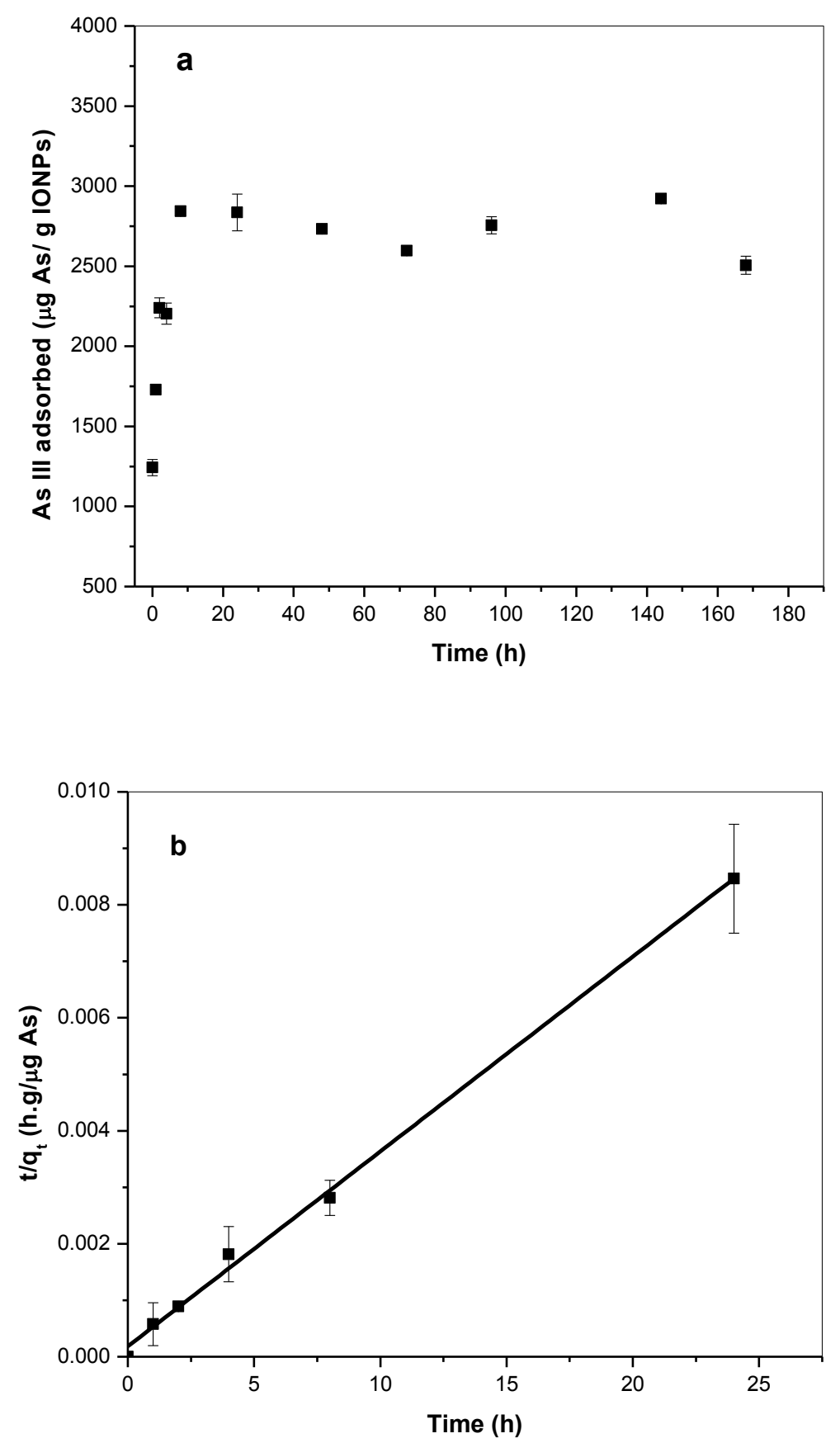
Figure 2:
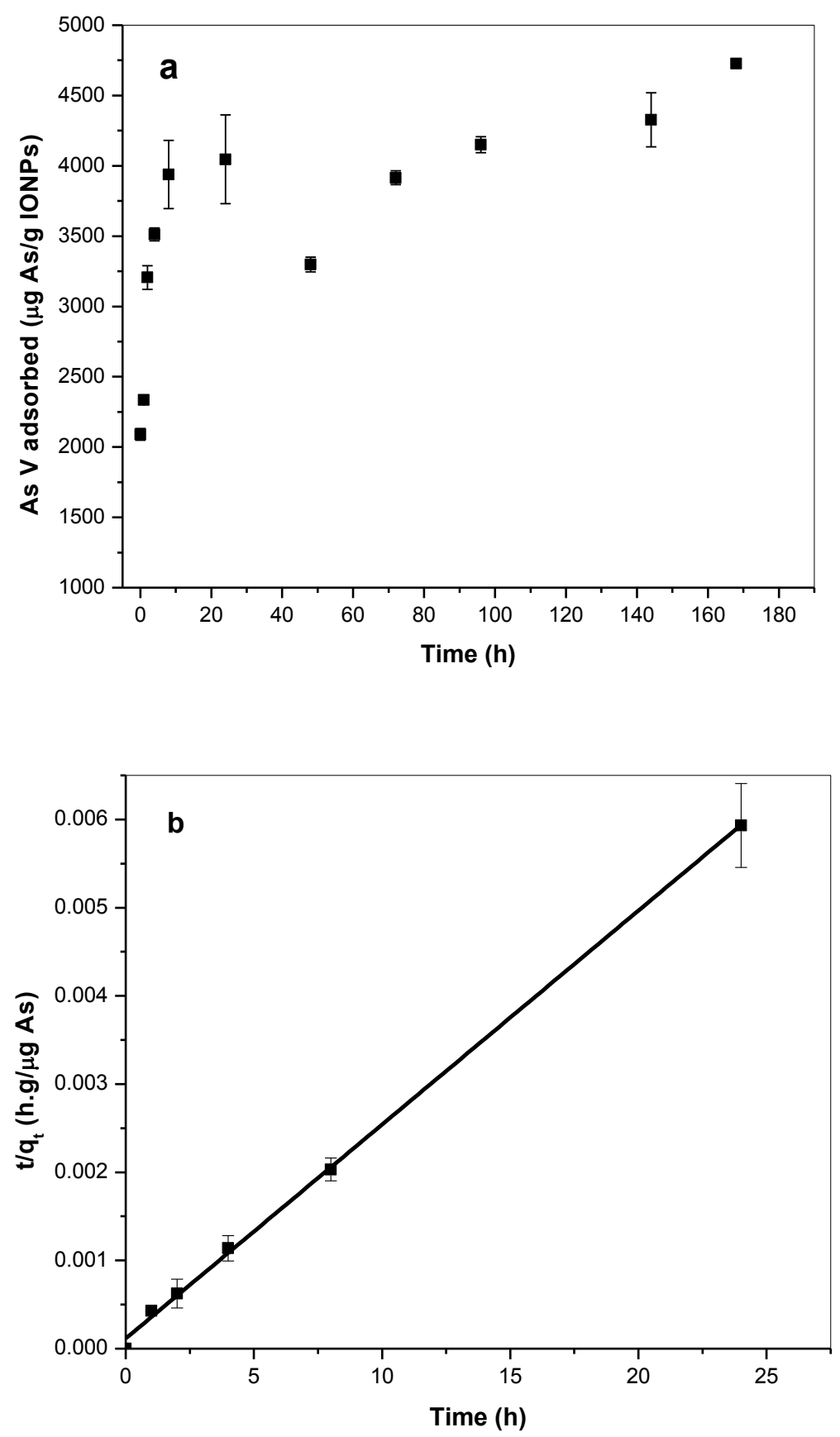
Figure 3
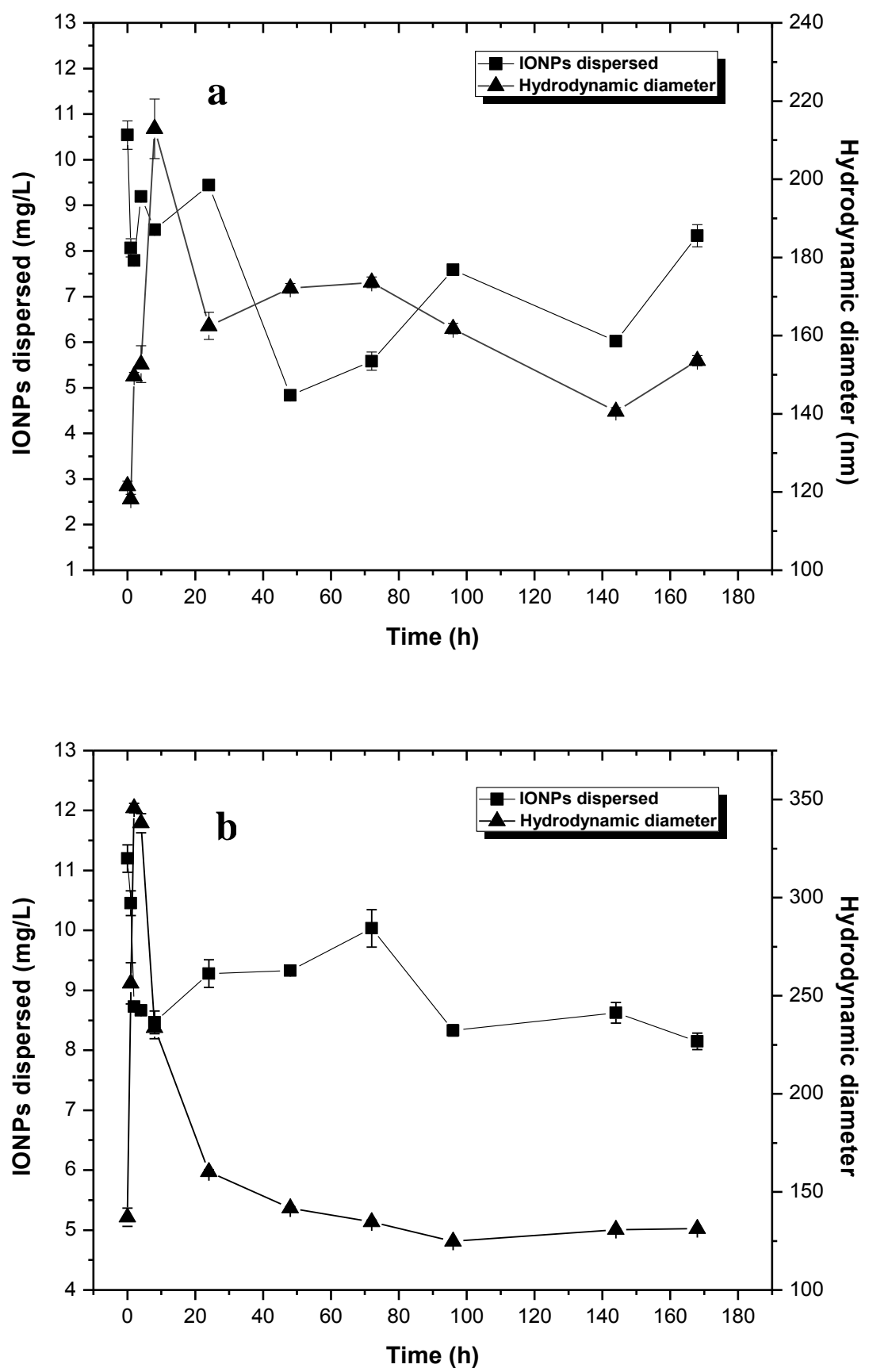
Figure 4
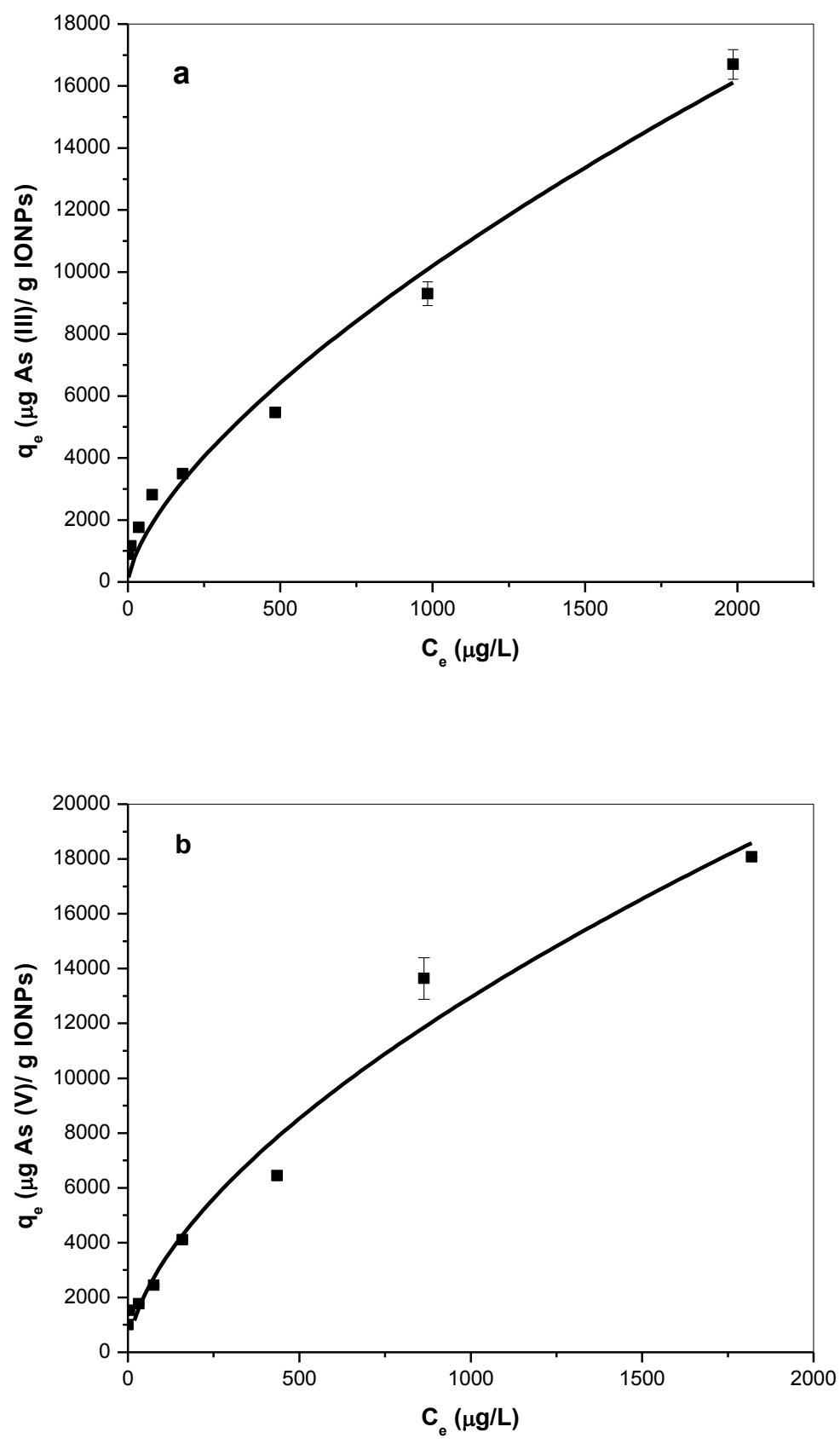
Figure 5
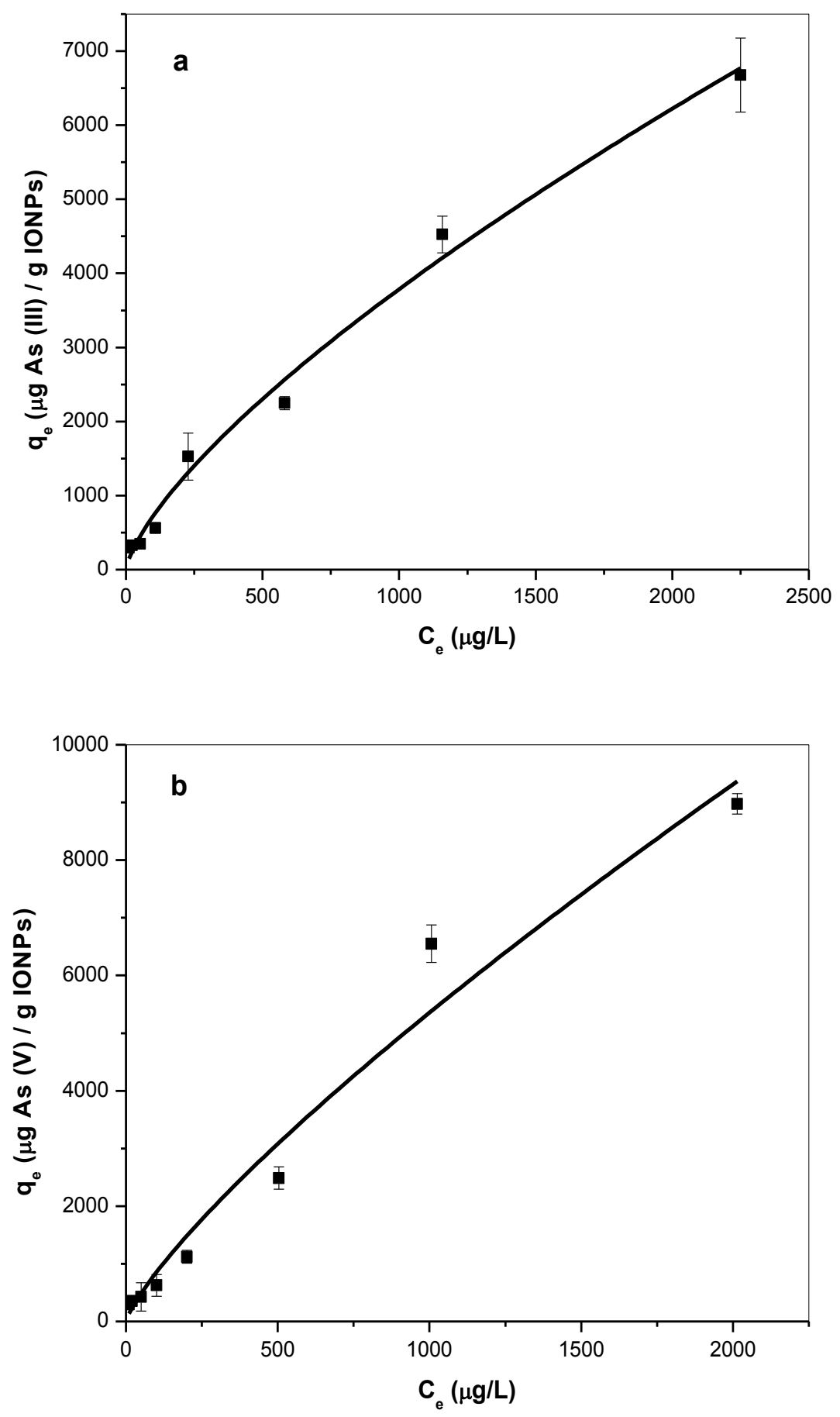
Table 1 Kinetic (pseudo second order) and Freundlich isotherm parameters for adsorption of As(III) and $\mathrm{As}(\mathrm{V})$ with hematite nanoparticles and hematite aggregates

\begin{tabular}{llllllll}
\hline Particle & Arsenic & Kinetics & & \multicolumn{3}{c}{ Isotherms } \\
& Species & & & & \\
& & $\mathrm{q}_{\mathrm{e}}(\mu \mathrm{g} / \mathrm{g})$ & $\mathrm{k}_{2}(\mathrm{~g} / \mu \mathrm{g} \cdot \mathrm{h})\left(10^{-4}\right)$ & $\mathrm{R}^{2}$ & $\mathrm{~K}_{\mathrm{f}}$ & $\mathrm{n}$ & $\mathrm{R}^{2}$ \\
& & & & & & & \\
\hline Hematite & As (III) & $2899 \pm 71.1$ & $6.45 \pm 3.11$ & 0.997 & $101 \pm 44.0$ & $1.50 \pm 0.13$ & 0.977 \\
nanoparticles & & & & & & & \\
& As (V) & $4122 \pm 62.8$ & $5.10 \pm 1.17$ & 0.999 & $200 \pm 92.2$ & $1.66 \pm 0.18$ & 0.969 \\
& & & & & & & \\
Hematite & As (III) & $1689 \pm 90.2$ & $6.45 \pm 1.39$ & 0.996 & $26.8 \pm 8.74$ & $1.40 \pm 0.09$ & 0.990 \\
aggregates & & & & & & & \\
& As (V) & $2614 \pm 72.7$ & $5.10 \pm 2.73$ & 0.986 & $21.5 \pm 14.4$ & $1.25 \pm 014$ & 0.968 \\
& & & & & & & \\
\hline
\end{tabular}

